\title{
ANALIZA PROCESU WRZENIA AMONIAKU O RÓŻNYM STOPNIU ZAOLEJENIA
}

\begin{abstract}
W pracy scharakteryzowano aktualny stan wiedzy w zakresie procesu wrzenia amoniaku przy przepływie w rurach poziomych. Przedstawiono wyniki badań własnych oraz danych literaturowych dotyczących zjawisk cieplno-przepływowych występujących podczas wrzenia amoniaku o różnym stopniu zaolejenia. W oparciu o zebrane wyniki badań dokonano analizy procesu pod kątem określenia wpływu stopnia zaolejenia czynnika oraz właściwości cieczy olejowych na warunki wnikania ciepła. Wskazano także na metody obliczeniowe przydatne dla opisu efektywności wnikania ciepła podczas wrzenia przy przepływie amoniaku w obecności oleju.
\end{abstract}

Słowa kluczowe: amoniak, wrzenie, wnikanie ciepła, struktury przepływu

\section{Wprowadzenie}

Z zakresu badań zjawisk zachodzących podczas wrzenia amoniaku w przepływie w kanałach, liczba publikacji jest bardzo ograniczona. Cytowane w literaturze opracowania odnośnie badań nad wrzeniem tego czynnika w rurach dotyczą w większości wyznaczania średnich wartości współczynnika wnikania ciepła oraz oporu przepływu, bądź też wprost współczynnika przenikania ciepła. Należy wymienić tutaj opracowania Boymana i in. [2], Daniłowej i in. [5,6], Maleka i Colina [10], Pieriedistajej [13,14], Rasczepkina [15], Sandru i Chiraca [17], Van Maalle i Cosijna [24], oraz Zhenga i in. [29]. Szereg danych odnośnie wcześniejszych opracowań można znaleźć w pracach Gogolina [7], Maczka [9] i Rubika [16] oraz Witczaka [25].

Pierwsze opracowania dotyczące procesu wrzenia amoniaku w ujęciu typowym dla przepływu mieszaniny dwufazowej datują się z lat 70-tych XX wieku i obejmują zagadnienia związane zarówno z wyznaczaniem struktur prze-

\footnotetext{
${ }^{1}$ Autor do korespondencji/corresponding author: Joanna Dratwa, Politechnika Opolska ul. Mikołajczyka 5, 45-271 Opole, tel.77 4498373

${ }^{2}$ Stanisław Witczak, Politechnika Opolska ul Mikołajczyka 5, 45-271 Opole, tel.77 449 8370, email: s.witczak@po.opole.pl
} 
pływu dwufazowego jak i określaniem lokalnych wartości współczynnika wnikania ciepła oraz oporu przepływu wywołanego tarciem.

$\mathrm{W}$ pracy przedstawiono aktualny stan wiedzy $\mathrm{w}$ zakresie oceny zjawisk cieplno-przepływowych występujących podczas wrzenia amoniaku o róznym stopniu zaolejenia przy jego przepływie w rurach poziomych. Wskazano jednocześnie na metody obliczeniowe zalecane dla różnych warunków procesu.

\section{Wyniki badań i ich analiza}

\subsection{Charakterystyka badań doświadczalnych}

Celem wskazania na zakres prac badawczych dotyczących oceny warunków wnikania ciepła podczas wrzenia przy przepływie amoniaku w rurach poziomych dokonano przeglądu szeregu opracowań, których charakterystykę $\mathrm{w}$ ujęciu chronologicznym przedstawiono $\mathrm{w}$ tabeli 1 . Przedstawiony w tym punkcie szczegółowy opis poszczególnych badań zawiera także informacje o analizie wyników badań wraz $\mathrm{z}$ oceną przydatności szeregu metod obliczeniowych w odniesieniu do warunków wrzenia amoniaku w rurach o różnych średnicach.

Tabela 1. Zakres badań doświadczalnych wrzenia amoniaku w kanałach poziomych

Table 1. Scope of experimental studies of the boiling of ammonia in horizontal channels

\begin{tabular}{|c|c|c|c|c|c|c|c|}
\hline Lp. & Autor & $\begin{array}{c}D \\
\mathrm{~mm}\end{array}$ & $\begin{array}{c}u_{o l} \\
\%\end{array}$ & $\begin{array}{c}g_{T} \\
\mathrm{~kg} /\left(\mathrm{m}^{2} \cdot \mathrm{s}\right)\end{array}$ & $x$ & $\begin{array}{c}q \\
\mathrm{~kW} / \mathrm{m}^{2}\end{array}$ & $\begin{array}{l}t_{n} \\
{ }^{\circ} \mathrm{C}\end{array}$ \\
\hline 1. & Shah $[18 \div 21]$ & 26,2 & - & $31 \div 1550$ & $0 \div 1$ & $0,58 \div 2,3$ & $-40 \div 0$ \\
\hline 2. & Chaddock i Buzard [3] & 13,4 & $0 \div 4,3$ & $16 \div 130$ & $0,08 \div 0,97$ & $1,5 \div 25,2$ & $-40 \div-23$ \\
\hline 3. & Witczak [25 $\div 27]$ & 20 & $0,25 \div 2$ & $20 \div 268$ & $0,06 \div 0,98$ & $1.7 \div 35,2$ & $-26,8 \div 14,2$ \\
\hline 4. & Kabelac i De Buhr [8] & 10 & - & $50 \div 150$ & $0 \div 0,9$ & $17 \div 75$ & $-40 \div 4,0$ \\
\hline 5. & Pamitran i in. [12] & $1,5 \div 3,0$ & - & $50 \div 600$ & $0 \div 1,0$ & $5,0 \div 70$ & $0 \div 10$ \\
\hline
\end{tabular}

Shah [18] prowadził badania wrzenia amoniaku w ogrzewanej elektrycznie stalowej rurze poziomej o średnicy wewnętrznej $26,2 \mathrm{~mm}$. W trakcie badań autor określał lokalne wartości współczynnika wnikania ciepła raz obserwował tworzące się struktury przepływu, w tym też obecność oleju w płynącej mieszaninie. Niestety układ aparaturowy nie pozwalał autorowi na ilościowe określenie jego udziału w przepływie. Badania prowadzone były w pełnym zakresie odparowania $x=0 \div 1$ przy zmianie gęstości strumienia masy $g_{T}=(31 \div 1550)$ $\mathrm{kg} /\left(\mathrm{m}^{2} \cdot \mathrm{s}\right)$, gęstości strumienia ciepła $q=(0,58 \div 2,3) \mathrm{kW} / \mathrm{m}^{2}$ oraz temperatury wrzenia $t_{n}=(-40 \div 0)^{\circ} \mathrm{C}$. Na podstawie dokonanych obserwacji struktur przepływu, autor stwierdził, że były one typowe dla przepływu dwufazowego gazciecz. Zakres ich występowania był zgodny z obszarami określonymi na mapie 
Bakera [1], którą autor zalecił do wykorzystania także dla warunków wrzenia amoniaku w rurach poziomych.

W kolejnych pracach Shaha $[19 \div 21]$ został poszerzony opis procesu wrzenia amoniaku dla różnych parametrów cieplno-przepływowych oraz zostały zaproponowane metody obliczania wartości współczynnika wnikania ciepła i oporów przepływu. Dla obliczania współczynnika wnikania ciepła autor opracował zależność graficzną, na podstawie której stwierdził, że efektywność procesu jest znacznie mniejsza niż w przypadku wrzenia freonów w tych samych warunkach. Przydatność opracowanej metody graficznej była jednak mała, gdyż w trakcie badań nie mierzono zawartości oleju w płynącym amoniaku, który to (także zdaniem autora) miał istotny wpływ na warunki wnikania ciepła.

Chaddock i Buzzard [3] prowadzili z kolei badania wrzenia amoniaku oraz freonu R502 w poziomej stalowej rurze o średnicy wewnętrznej $D=13,4 \mathrm{~mm}$ i długości $1,83 \mathrm{~m}$. W zakresie wrzenia amoniaku badania obejmowały wyznaczanie wartości współczynnika wnikania ciepła $\mathrm{w}$ odniesieniu do czystego czynnika jak i amoniaku zanieczyszczonego olejem mineralnym. W cytowanej publikacji większość miejsca poświęcono badaniom wrzenia freonu R502 i dla tego czynnika przeprowadzono pełną analizę wyników. W zakresie badań wrzenia amoniaku, prowadzonych w zakresie $g_{T}=(16 \div 130) \mathrm{kg} /\left(\mathrm{m}^{2} \cdot \mathrm{s}\right), q=$ $(1,5 \div 25,2) \mathrm{kW} / \mathrm{m}^{2}, t_{n}=(-40 \div-23){ }^{\circ} \mathrm{C}$ oraz $x=0,08 \div 0,97$, autorzy ograniczyli się do komentarza dotyczącego wpływu gęstości strumienia ciepła oraz udziału masowego pary na wartość współczynnika wnikania ciepła. W odniesieniu do wrzenia amoniaku wolnego od oleju, autorzy stwierdzili, że proces jest analogiczny jak dla odparowania konwekcyjnego innych cieczy chłodniczych. Z kolei dla wrzenia amoniaku o udziale masowym oleju do 4,3\%, autorzy stwierdzili istotny wpływ udziału oleju na obniżenie wartości współczynnika wnikania ciepła. Ich zdaniem, było to prawdopodobnie związane $\mathrm{z}$ osiadaniem oleju na ściankach rury. Wykorzystywany w obiegu sprężarkowym olej mineralny miał gęstość $\rho_{\mathrm{ol}} \approx 900 \mathrm{~kg} / \mathrm{m}^{3}$, a dynamiczny współczynnik lepkości w zakresie $t_{n}=$ $(-30 \div 22){ }^{\circ} \mathrm{C}$ wynosił $\eta_{\mathrm{ol}}=(100 \div 200) \mathrm{mPa} \cdot \mathrm{s}$. Autorzy omawianej pracy [3] nie podjęli jednak próby znalezienia równań opisujących warunki wnikania ciepła oraz wartości oporów przepływu dla tego czynnika, stwierdzają jedynie, że znane im zależności dla obliczania badanych wielkości, nie opisują z zadowalającą dokładnością danych doświadczalnych.

Witczak [25] zrealizował obszerne badania nad wrzeniem amoniaku, które prowadzone były na stanowisku badawczym pracującym równolegle z przemysłowym amoniakalnym obiegiem chłodniczym na terenie dużej chłodni składowej. Zasadnicze badania obejmowały określenie wpływu podstawowych parametrów cieplno-przepływowych i stopnia zaolejenia czynnika na wartości współczynnika wnikania ciepła podczas wrzenia amoniaku w stalowych rurach o średnicy $20 \mathrm{~mm}$. W przypadku wykorzystania amoniaku czystego, zakres zmian podstawowych parametrów cieplno-przepływowych charakterystycznych 
dla odparowania podczas przepływu wynosił: $\mathrm{g}_{T}=(20 \div 268) \mathrm{kg} /\left(\mathrm{m}^{2} \cdot \mathrm{s}\right), q=$ $(1680 \div 35179) \mathrm{W} / \mathrm{m}^{2}, x=(0,06 \div 0,98)$ oraz $t_{n}=(-26,8 \div 14,2){ }^{\circ} \mathrm{C}$. Z kolei dla amoniaku zaolejonego parametry te zmieniano odpowiednio: $g_{T}=(50 \div 135)$ $\mathrm{kg} /\left(\mathrm{m}^{2} \cdot \mathrm{s}\right), q=(10533 \div 24625) \mathrm{W} / \mathrm{m}^{2}, x=(0,10 \div 0,89)$ i $t_{n}=(-11,4 \div 2,1){ }^{\circ} \mathrm{C}$. Stopień zaolejenia czynnika, ustalany poprzez dozowanie oleju do wrzącego amoniaku, wynosił średnio $0,25 \%, 0,5 \%, 1 \%$ i $2 \%$ mas. Wybrane zmierzone I obliczone właściwości, stosowanego w badaniach oleju mineralnego o średniej gęstości $\rho_{o l} \approx 910 \mathrm{~kg} / \mathrm{m}^{3}$, w zakresie temperatury $(-20 \div 10){ }^{\circ} \mathrm{C}$, wynosiły odpowiednio: $\quad c_{\mathrm{ol}}=(1699 \div 1806) \mathrm{J} /(\mathrm{kg} \cdot \mathrm{K}), \quad \eta_{\mathrm{ol}}=(935 \div 133) \mathrm{mPa} \cdot \mathrm{s}, \quad \lambda_{\mathrm{ol}}=$ $(0,130 \div 0,128) \mathrm{W} /(\mathrm{m} \cdot \mathrm{K})$ oraz $\sigma_{\mathrm{ol}}=(33,8 \div 27,2) \mathrm{mN} / \mathrm{m}$. Stosowany $\mathrm{w}$ badaniach zakres zmian poszczególnych parametrów został dobierany tak, aby odzwierciedlał warunki pracy parowników przemysłowych.

$\mathrm{W}$ wyniku przeprowadzonych badań stwierdzono, że proces wrzenia czystego amoniaku przy przepływie $\mathrm{w}$ rurach, pod względem mechanizmu wnikania ciepła, jest podobny do wrzenia innych czynników chłodniczych. Uzyskiwanie w badaniach stosunkowo niskich wartości współczynnika wnikania ciepła w stosunku do oczekiwanych, związane było z izolacyjnym oddziaływaniem błony olejowej osadzającej się na powierzchni rur. Szereg dodatkowych informacji w tym zakresie zawierają opracowania [26:28]. W cytowanych pracach dokonywano także oceny dokładności metod obliczania współczynnika wnikania ciepła, w odniesieniu do warunków wrzenia amoniaku. Najwyższe dokładności uzyskiwano dla metod Chena [4], Mikielewicza [11], Steinera [22], oraz Troniewskiego [23], przy czym ich dokładność wynosiła od 50 do 100\%, a spowodowane to było obecnością już niewielkiej ilości oleju we wrzącym czynniku. Stwierdzona stosunkowo małą dokładność metod stosowanych do obliczania tych wielkości dla innych czynników chłodniczych, była podstawą do opracowania własnych metod, zapewniających odpowiednio wyższą dokładność obliczeniową.

Kabelac i De Buhr [8] przeprowadzili badania eksperymentalne wrzenia czystego amoniaku przy przepływie $\mathrm{w}$ poziomej rurze gładkiej oraz $\mathrm{w}$ rurze $\mathrm{z}$ mikrożebrami. Rury były ogrzewane przeponowo kondensującą się parą amoniaku o wyższym ciśnieniu. Rura gładka miała średnicę wewnętrzną $10 \mathrm{~mm}$ a rura ze spiralnym karbowaniem niskich żeber (21 kwadratowych żeber w kształcie płetwy na obwodzie, przy jej wysokość $0,63 \mathrm{~mm}$ i kącie spirali $25^{\circ}$ ) miała maksymalną średnicę wewnętrzną $11,13 \mathrm{~mm}$. W obu przypadkach mierzone były lokalne współczynniki wnikania ciepła oraz określane były struktury przepływu dwufazowego. Zakres zmian podstawowych parametrów przepływowych i cieplnych wynosił odpowiednio: $g_{T}=(50 \div 150) \mathrm{kg} /\left(\mathrm{m}^{2} \cdot \mathrm{s}\right), q=$ $(17 \div 75) \mathrm{kW} / \mathrm{m}^{2}, x=0 \div 0,9$ oraz $t_{n}=(-40 \div 4,0)^{\circ} \mathrm{C}$. W odniesieniu do charakteru przepływu dwufazowego, obserwowano struktury falowe, korkowe i rzutowe oraz różne formy przepływu pierścieniowego i intermitentnego, które miały 
istotny wpływ na wartości współczynnika wnikania ciepła. Autorzy stwierdzili przy tym, że dane eksperymentalne dotyczące wnikania ciepła w rurze gładkiej dla niskich wartości gęstości strumienia masy były stosunkowo dobrze opisane przez model Steinera [22]. W temperaturze około $0^{\circ} \mathrm{C}$, rury z żebrami zapewniały poprawę wymiany ciepła tylko ze względu na zwiększenie powierzchni. W rzeczywistości, autorzy stwierdzili, że badane ożebrowanie rury nie przyczyniło się w istotnym stopniu do poprawy wnikania ciepła.

Pamitran i in. [12] przeprowadzili badania wnikania ciepła podczas wrzenia przy przepływie w minikanałach trzech naturalnych czynników chłodniczych, a mianowicie amoniaku, dwutlenku węgla oraz propanu. Badania wrzenia prowadzono w poziomych, ogrzewanych elektrycznie stalowych rurkach o średnicach 1,5 i $3 \mathrm{~mm}$ i długości $2,0 \mathrm{~m}$. Celem oceny wpływu wybranych parametrów cieplno-przepływowych na warunki wnikania ciepła dla każdego z czynników, badania prowadzono w zakresie zmian: $g_{T}=(50 \div 600) \mathrm{kg} /\left(\mathrm{m}^{2} \cdot \mathrm{s}\right), q=(5,0 \div 70)$ $\mathrm{kW} / \mathrm{m}^{2}, x=0 \div 1,0$ oraz $t_{n}=(0 \div 10)^{\circ} \mathrm{C}$. Autorzy dokonali porównania efektywności wnikania ciepła względem badanych czynników i stwierdzili, wartości współczynników wnikania ciepła dla amoniaku są pośrednie w stounku do wartości uzyskiwanych dla dwutlenku węgla i propanu. Z uwagi na brak zgodności uzyskanych wyników z wartościami obliczonymi z dostępnymi w literaturze korelacjami dla wrzenia w minikanałach, zaproponowali własną korelację do obliczania wartości współczynnika wnikania ciepła, będącą modyfikacją metody Chena [4].

\subsection{Analiza warunków wnikania ciepła}

$\mathrm{Z}$ uwagi na bardzo małą liczbę danych doświadczalnych dotyczących wnikania ciepła podczas wrzenia naturalnych czynników w kanałach o różnej geometrii, przykładową analizę warunków wnikania ciepła przeprowadzono na podstawie własnych wyników badań uzyskanych przez autora [25] dla wrzenia amoniaku w rurach poziomych.

Celem jakościowej oceny wpływu podstawowych parametrów cieplnoprzepływowych na wartość współczynnika wnikania ciepła podczas wrzenia amoniaku w rurach wykonano wykresy typu: $\alpha_{2 F}=\mathrm{f}\left(x, g_{T}\right)$ oraz $\alpha_{2 F}=\mathrm{f}(x, q)$, które dla przykładowych danych doświadczanych zestawiono na rys.1. Z rozkładu danych doświadczalnych przedstawionych na wykresach wynika, że w przypadku wrzenia czystego amoniaku wartość współczynnika wnikania ciepła zależy zarówno od parametrów przepływowych jak i cieplnych. Dla stałej wartości gęstości strumienia masy $\left(g_{T}=\right.$ const $)$, ze wzrostem udziału masowego pary następuje początkowo zwiększenie wartości współczynnika wnikania ciepła, a następnie jego zmniejszenie. Występowanie maksimum funkcji $\alpha_{2 F}=\mathrm{f}\left(g_{T}, x\right)$ związane jest z występowaniem tzw. „kryzysu wrzenia drugiego rodzaju” polegającego na tworzeniu się suchych miejsc na powierzchni ścianki rury w wyni- 
ku intensywnego odparowania filmu cieczy, bądź poprzez jego zrywanie, przez płynącą ze znaczną prędkością, fazę parową.

a)

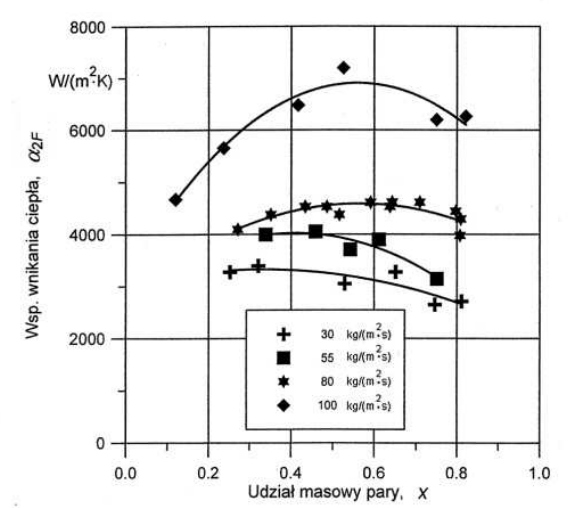

b)

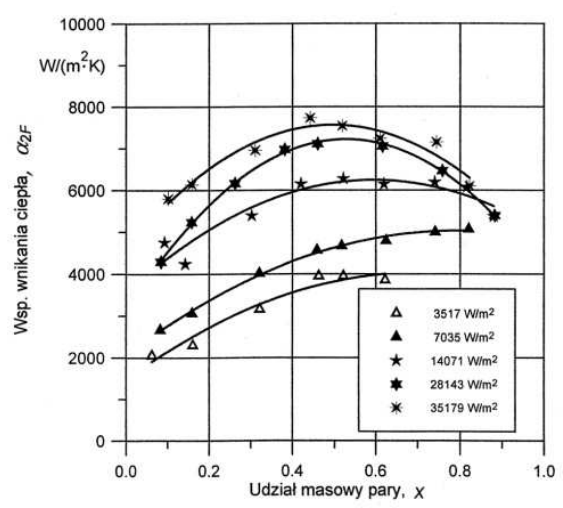

Rys.1. Współczynnik wnikania ciepła podczas wrzenia amoniaku przy przepływie w rurze o średnicy $20 \mathrm{~mm}$, dla: a) $q=16,8 \mathrm{~kW} / \mathrm{m}^{2}$ i $t_{n} \approx-10^{\circ} \mathrm{C}$, b) $g_{T}=80 \mathrm{~kg} /\left(\mathrm{m}^{2} \cdot \mathrm{s}\right)$ i $t_{n} \approx-18^{\circ} \mathrm{C}$

Fig.1. Convective heat-transfer coefficient during boiling of ammonia in pipe of diameter $20 \mathrm{~mm}$ for: a) $q=16.8 \mathrm{~kW} / \mathrm{m}^{2}$ and $t_{n} \approx-10^{\circ} \mathrm{C}$, b) $g_{T}=80 \mathrm{~kg} /\left(\mathrm{m}^{2} \cdot \mathrm{s}\right)$ and $t_{n} \approx-18^{\circ} \mathrm{C}$

Z kolei wpływ gęstości strumienia ciepła na wartość $\alpha_{2 F}$ nie jest tak jednoznaczny. Dla $g_{T}=$ const jest on znaczący dla małych wartości udziału masowego pary i stopniowo maleje ze wzrostem $x$. Również w tym przypadku występuje maksimum wartości współczynnika wnikania ciepła, przy czym wzrost $q$ powoduje jego występowanie dla coraz mniejszych wartości $x$. Uwzględniając przebiegi funkcji $\alpha_{2 F}=\mathrm{f}\left(x, g_{T}\right)$ oraz $\alpha_{2 F}=\mathrm{f}(x, q)$ należy stwierdzić, że proces wrzenia ma charakter zarówno odparowania konwekcyjnego jak i wrzenia pęcherzykowego z nałożoną konwekcją wymuszona. Można zatem stwierdzić, że proces wrzenia amoniaku podczas przepływu w rurach, pod względem mechanizmu wnikania ciepła jest analogiczny jak w przypadku wrzenia innych czynników chłodniczych, w tym także czynników naturalnych. Uzyskiwanie w badaniach wrzenia amoniaku stosunkowo niskich wartości współczynnika wnikania ciepła w stosunku do oczekiwanych, związane było w wielu przypadkach z izolacyjnym oddziaływaniem błony olejowej osadzającej się na powierzchni rur. Wpływ stopnia zaolejenia wyraźnie widać w przypadku gdy ilość oleju jest znaczna.

Jak wynika $\mathrm{z}$ przykładowych danych zawartych na rys.2, zwiększenie udziału masowego oleju we wrzącym amoniaku w granicach do $2 \%$, powoduje zarówno kilkakrotny spadek wartości współczynnika wnikania ciepła jak i zmienia charakter zależności $\alpha_{2 F}=\mathrm{f}\left(x, g_{T}\right)$. 


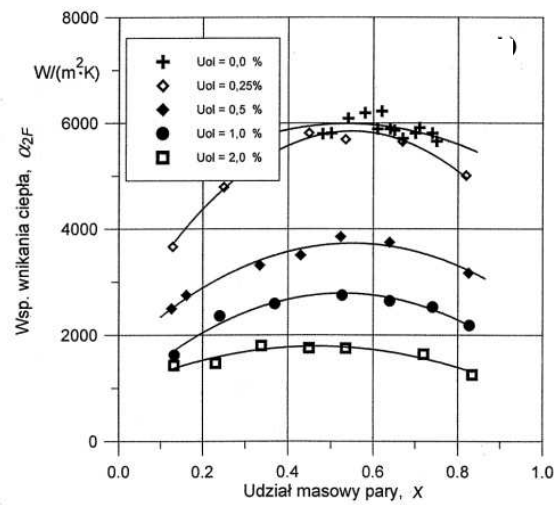

Rys.2.Wpływ stopnia zaolejenia amoniaku na wartość współczynnika wnikania ciepła przy wrzeniu w rurze poziomej o średnicy $D=20$ $\mathrm{mm}$ dla $g_{T}=130 \mathrm{~kg} /\left(\mathrm{m}^{2} \cdot \mathrm{s}\right), q=16,8 \mathrm{~kW} / \mathrm{m}^{2}$ i $t_{n} \approx 0^{\circ} \mathrm{C}$

Fig.2. Influence of an extent of oiling in ammonia on the value of convective heat-transfer coefficient during boiling in horizontal pipe of $D=20 \mathrm{~mm}$ for $g_{T}=130 \mathrm{~kg} /\left(\mathrm{m}^{2} \cdot \mathrm{s}\right), q=16.8$ $\mathrm{kW} / \mathrm{m}^{2}$ and $t_{n} \approx 0^{\circ} \mathrm{C}$

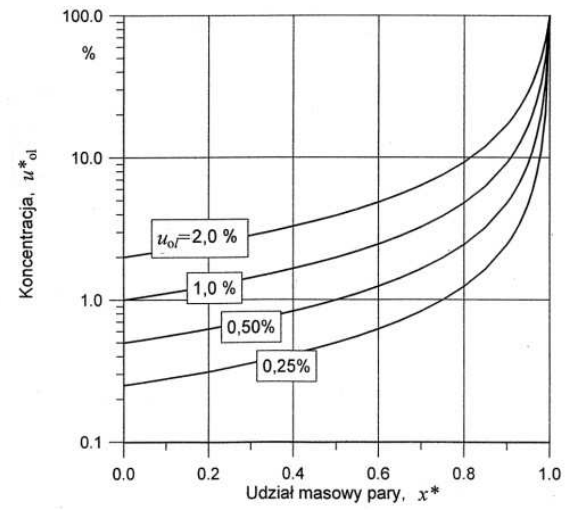

Rys. 3. Wpływ udziału masowego pary oraz oleju w mieszaninie parowo-cieczowej na wartość koncentracji oleju w fazie ciekłej

Fig. 3. Influence of the vapour and oil mass fractions in the steam-liquid mixture on the value of extent of oiling in liquid phase

O ile dla $u_{o l}=0 \%\left(g_{o l}=0\right)$ zależność ta wykazuje maksimum wartości $\alpha_{2 F}$, to ze zwiększeniem zawartości oleju maksimum to zanika. Zmniejszanie się wartości $\alpha_{2 F, o l}$ ze zwiększeniem $u_{o l}$ i $x$ związane jest ze wzrostem koncentracji oleju w ciekłym amoniaku

$$
u_{o l}^{*}=\frac{g_{o l}}{g_{c, \mathrm{NH}_{3}}+g_{o l}}=\frac{g_{o l}}{g_{T}-g_{g}}=\frac{u_{o l}}{1-x} .
$$

Jak pokazano na rys.3, zmiana koncentracji oleju w fazie ciekłej może wynosić od $u_{\mathrm{ol}}{ }^{*}=u_{\mathrm{ol}}$ dla $x^{*}=0$ do $u_{\mathrm{ol}}{ }^{*}=1 \mathrm{w}$ przypadku pełnego odparowania amoniaku, czyli przy $x^{*}=1$. Udział masowy pary $x^{*}$ oznacza w tym przypadku zawartość fazy parowej uzyskanej w wyniku odparowania amoniaku wolnego od oleju, tj.

$$
x^{*}=\frac{g_{g}}{g_{g}+g_{c, \mathrm{NH}_{3}}}=\frac{g_{g}}{g_{T}-g_{o l}}=\frac{x}{1-u_{\mathrm{ol}}} .
$$

Należy zaznaczyć, że tendencja zmian wartości współczynnika wnikania ciepła ze wzrostem koncentracji oleju w cieczy, będzie miała miejsce w każdym przypadku wrzenia, w którym olej jest składnikiem nie mieszającym się z cieczą odparowywaną, co potwieredzają także wyniki badań Chaddocka i Buzzar- 
da [3]. W warunkach wrzenia takiej mieszaniny na ściankach kanału będzie tworzyć się ,izolacyjna” warstewka oleju, której grubość zależeć będzie nie tylko od parametrów przepływowych i udziału masowego pary we wrzącej mieszaninie, ale również od zawartości oleju w mieszaninie i jego właściwości fizykochemicznych. Stąd też istotne różnice w opisywanych wynikach badań różnych autorów i brak możliwości uogólnienia metod obliczeniowych wartości współczynnika wnikania ciepła. Nie mniej jednak, dla znanej zawartości oleju w amoniaku, można wykazać, że stosunek wartości współczynnika wnikania ciepła podczas wrzenia amoniaku zaolejonego $\alpha_{2 F, o l}$ do wartości uzykiwanej (w tych samych warunkach cieplno-przepływowych) podczas wrzenia amoniaku wolnego od oleju $\alpha_{2 F, 0}$ jest zawsze mnuiejszy od jedności. Dla ilościowego opisu tej relacji, opacowano w oparciu o dane doświadczalne z badań własnych oraz danych Chaddocka i Buzzarda [3], następującą zależność

$$
\frac{\alpha_{2 F, o l}}{\alpha_{2 F, 0}}=\exp \left[-6,15\left(u_{o l}^{*}\right)^{0,55}\right]
$$

dla której wartość współczynnika korelacji wynosi $\mathrm{r}=0,84$ a średnia wartość odchylenia standardowego 0,32. Zdając sobie sprawę z ograniczonej dokładności tej relacji, planuje się kontynuację działań celem dokładniejszego opisu warunków wnikania ciepła dla wrzenia amoniaku w obecności fazy olejowej.

\section{Podsumowanie}

W oparciu o przeprowadzą analizę wyników badań wrzenia amoniaku podczas przepływu $\mathrm{w}$ kanałach stwierdzono, iż brak jest jednoznaczności w opisie występujących zjawisk oraz zaleceń co do wyboru odpowiednio dokładnych metod obliczania wartości współczynnika wnikania ciepła. Przedstawione propozycje metod obliczeniowych przez poszczególnych autorów należy traktować jako słuszne tylko w określonych warunkach procesu. Należy sądzić, że dalsze prace w tym zakresie pozwolą na uściślenie opisu zjawisk mających miejsce podczas wrzenia amoniaku o róznym stopniu zaolejenia.

\section{Literatura}

[1] Baker O.: Simultaneous flow of oil and gas, Oil Gas J., 53 (1954) 183-195.

[2] Boyman T., Aecherli P., Steiner A.: Flow boiling of ammonia in smooth horizontal tubes in the presence of immiscible oil, Int. Refrigeration and Air Conditioning Conf., Purdue 2004.

[3] Chaddock J.B., Buzzard G.: Film coefficient for in tube evaporation of ammonia and R-502 with and without small percentages of mineral oil (RP-224), ASHRAE Trans., 92 (1986) 22-40. 
[4] Chen J.C.: A correlation for boiling heat transfer to saturated fluid in convective flow, Industrial and Engineering Chemistry, Process Design Development, 5 (1966) 322-329.

[5] Danilova G.N., Kuprianova A.B.: Obobszczenija dannych po tieplootdaczi pri kipienii ammiaka, Cholodilnaja Tiechnika, 6 (1971) 23-25.

[6] Danilova G.N., Malugin G.I., Malkov L.S.: Eksperimentalnoje islelovanije teplooddaci pri kipienii ammiaka w vertikalnych kolcievych kanalach, Cholodilnaja Tiechnika, 9 (1975) 32-36.

[7] Gogolin A.A.: Intensifikacja teploobmena w isparitielach cholodilnych maszin, Izd. Liekkaja i piszewaja promyszlennost, Moskva 1982.

[8] Kabelac S., De Buhr H.J.: Flow boiling of ammonia in a plain and low finned horizontal tube, Int. J. Refrigeration, 24 (2001) 41-50.

[9] Maczek K., Mieczyński M.: Chłodnictwo, Skrypt Politechniki Wrocławskiej, Wrocław 1981.

[10] Malek A., Colin R.: Etude experimentale du transfert de chaleur et des pertes de charges de l'ammoniac a'ecoulant a l'interieur d'un tube long, Rev. Geri. Therm. Fr., 277 (1985) 23-40.

[11] Mikielewicz J.: Modelowanie procesów cieplno-przepływowych, Wydawnictwo PAN, Zakład Narodowy im. Ossolińskich, Wrocław 1995.

[12] Pamitran A.S., Choi K., Nasruddin J.T. : Evaporation heat transfer coefficient in single circular small tubes for flow natural refrigerants of $\mathrm{C} 3 \mathrm{H} 8, \mathrm{NH} 3$, and $\mathrm{CO}$, Int. J. Multiphase Flow, 37 (2011) 794-801.

[13] Pieriedistaja R.P.: Metod rasczeta padienija dawlienija w cirkuljacionnom konturie nasosnych ochłazdajuszczich sistiem z dwuchfaznym tieczeniem ammiaka, Cholodilnaja Technika, 3 (1977) 33-37.

[14] Pieriedistaja R.P., Danilova G.N.: Eksperimentalnoje isledovanija wnutriennej teplooddaci w wozduchnochladitielach z niznej podaciej ammiaka, Cholodilnaja Technika, 2 (1976) 19-23.

[15] Rascepkin A.N., Danilova G.N., Azarskov W.M.: Teplootdacza pri dwizieni dwuchfaznogo potoka smiesiej ammiaka s maslom w obogriewajemych zmievikach, Cholodilnaja Tiechnika, 9 (1991) 7-10.

[16] Rubik M.: Chłodnictwo, WNT, Warszawa 1979.

[17] Sandru E., Chirac F.: Heat transfer for the vaporization of ammonia during flow through horizontal pipe system under conditions of low vapor concentration, Int. Chem. Eng., 18 (1978) 692-699.

[18] Shah M.M.: Heat transfer and pressure drop in ammonia evaporators, ASHRAE Trans., 80 (1974) 238-254.

[19] Shah M.M.: Visual observation in an ammonia evaporator, ASHRAE Trans., 81 (1975) 295-306. 
[20] Shah M.M.: A new correlation for heat transfer during boiling flow through pipes, ASHRAE Trans., 82 (1976) 66-86.

[21] Shah M.M.: Heat transfer, pressure drop, visual observation, test data for ammonia evaporating inside pipes, ASHRAE Trans., 84 (1978) 38-59.

[22] Steiner D.: Heat transfer to boiling saturated liquids, VDI Head Atlas, Düsseldorf 1993.

[23] Troniewski L.: Metoda obliczania procesu odparowania w rurach w obszarze konwekcyjnym, ZN WSI Opole, s. Mechanika, 9, Opole 1977.

[24] Van Maale J., Cosijn E.A.: Coder output asce function of the recirculation number of the refrigerant, Proc. of 12th Int. Congress of Refrigeration, 1975.

[25] Witczak S.: Półempiryczny model procesów cieplno-przepływowych przy wrzeniu amoniaku w rurach, Studia i Monografie z. 91, Politechnika Opolska, Opole 1997.

[26] Witczak S.: Modelowanie procesów cieplno-przepływowych przy wrzeniu amoniaku w rurach, XVII Zjazd Termodynamików, Kraków 1999.

[27] Witczak S.: Wnikanie ciepła podczas wrzenia amoniaku w rurach, Inż. Chem. i Proc., 22 (2001) 1489-1494.

[28] Witczak S.: Wrzenie naturalnych czynników chłodniczych podczas przepływu w kanałach I minikanałach, Wyd. Politechniki Opolskiej, Opole 2013.

[29] Zheng J.X., JIN G.P., CHYO M.C., AYUB Z.H.: Boiling of ammonia/lubricant mixture on a horizontal tube in a flooded evaporator with inlet vapor quality, Exp. Therm. Fluid Sci., 30 (2006) 223-231.

\section{ANALYSIS OF AMMONIA BOILING PROCESS WITH DIFFERENT EXTENT OF OILING}

\section{S u m m a r y}

The paper presents the current state of knowledge on ammonia boiling at flow in horizontal pipes. The results of author's own research as well as the literature data on the heat flow phenomena during boiling of ammonia with different extent of oiling are described. Based on the collected results the analysis of the process was made in order to determine an impact of extent of agent oiling and its properties on the heat transfer conditions. The paper also indicates computational methods which are useful for describing the efficiency of heat transfer during boiling at ammonia flow in the presence of oil.

Key words: ammonia, boiling, heat transfer, flow structures

DOI: $10.7862 / \mathrm{rm} .2014 .36$

Otrzymano/received: 25.05 .2014

Zaakceptowano/accepted: 28.06 .2014 